\title{
A prospective randomized trial to compare side effects of early versus late removal of Foley's catheter and vaginal pack following vaginal hysterectomy
}

\author{
Ayesha Gupta*, Reddi Rani P.
}

Department of Obstetrics and Gynecology, Mahatma Gandhi Medical College and Research Institute, Pondicherry, India

Received: 23 January 2018

Revised: 01 March 2018

Accepted: 06 March 2018

\section{*Correspondence:}

Dr. Ayesha Gupta,

E-mail: ayesham.gupta@gmail.com

Copyright: (C) the author(s), publisher and licensee Medip Academy. This is an open-access article distributed under the terms of the Creative Commons Attribution Non-Commercial License, which permits unrestricted non-commercial use, distribution, and reproduction in any medium, provided the original work is properly cited.

\section{ABSTRACT}

Background: There is a controversy about the ideal time for removal of catheter and vaginal pack following vaginal hysterectomy. The present study was undertaken to compare post-operative morbidity in early and late removal of Foley's catheter and vaginal pack. The aim of this study is to compare post-operative morbidity in early and late removal of Foley's catheter and vaginal pack following vaginal hysterectomy.

Methods: This was a prospective randomized study with $n=100$ of those women who were undergoing vaginal hysterectomy with or without pelvic floor repair and fulfilled the inclusion criteria. After informed written consent, they were assigned to Foley's catheter and vaginal pack removal group in 6 hours (group I, n=50) or 24 hours removal group (group II, $\mathrm{n}=50$ ). Primary parameters used to assess were urine routine and microscopy, urine culture and sensitivity on post-operative day 2 , need for re-catheterization and repacking, febrile morbidity, ambulation, vault infection and post-operative hospital stay duration were analyzed in both groups.

Results: Febrile morbidity was found in $6 \%$ and $8 \%$, Positive urine culture was found in $10 \%$ and $20 \%$, Rate of recatheterization was $10 \%$ in group I and group II respectively. Vaginal bleeding after pack removal and repacking was in $6 \%$ in group I whilst none had in group II.

Conclusions: Early removal was associated with less incidence of urinary tract infection, and increased rate of recatheterization and repacking. Needs larger comparative studies to support the practice of early removal.

Keywords: Foley's catheter, Recatheterization, Urinary infection, Vaginal pack

\section{INTRODUCTION}

Hysterectomy is one of the most common gynecological surgeries performed worldwide with 600,000 hysterectomies being performed in United States itself per year. ${ }^{1}$

Traditionally abdominal hysterectomy is the common approach worldwide. However today there are several different methods of performing hysterectomy, such as total laparoscopic hysterectomies, laparoscopic assisted vaginal hysterectomy (LAVH), robotic assisted vaginal hysterectomy and vaginal hysterectomy. Over the years Vaginal Hysterectomy (VH), LAVH and robotic assisted $\mathrm{VH}$ are gaining popularity and are replacing abdominal hysterectomy. American college of obstetricians and gynecologists strongly recommend vaginal hysterectomy be the route of choice, wherever feasible for women with 
benign pathology in whom hysterectomy is indicated. ${ }^{2}$ The reasons in advocating so are more favorable outcomes when compared to abdominal hysterectomy such as shorter operative duration, speedier recovery, less pain and better quality of life. ${ }^{3}$ The common conditions in which vaginal hysterectomy is indicated are Fibroid <16weeks, Adenomyosis, Dysfunctional Uterine Bleeding and Utero-Vaginal prolapse. The choice of this route is multi-factorial, as it not only depends on the recommendations and indications of $\mathrm{VH}$, but also surgeon's expertise and training, their level of confidence and comfort in performing $\mathrm{VH}$ and the extent of uterine descent. ${ }^{4}$

It has been a routine practice to place a vaginal pack following $\mathrm{VH}$ to prevent reactionary hemorrhage and also continuous bladder drainage with Foley's catheter to assess urinary output and to prevent post op. urinary retention. But this is accompanied with increased risk of urinary tract infection (UTI), inconvenience for patients, higher costs and prolonged hospital stay. In $\mathrm{VH}$, nerve supply is not much disturbed, so short-term catheterization is being tried. The best way to prevent catheter related UTI is to avoid catheterization if possible or removal of catheter as early as possible. There is a controversy about the ideal time for removal of catheter after surgery as the decision of the duration of catheter post operatively is based more upon the hospital protocols, surgeon's preference, evidence-based knowledge rather than any strict guideline. ${ }^{5}$ Studies have shown 3 to $10 \%$ increased risk of bacteriuria per day of catheterization. ${ }^{6}$

Present study was done to compare the complications and outcome when the vaginal pack and urinary catheter were removed after 6 hours or after 24 hours post operatively.

Objectives were to:

- To assess febrile morbidity, urinary tract infection, re-catheterization, pain perception, voiding difficulty, vaginal bleeding and duration of hospital stay.

- To compare the incidence of the complications in the two groups of women in whom the urinary catheter and vaginal pack removal after 6 hours and 24 hours.

\section{METHODS}

This was a prospective randomized comparative study. Patients were recruited for the study after informed and written consent and the study was conducted at $\mathrm{MGMCH}$ and RI over a period of fifteen months (December 2015March 2017). All the patients who were fulfilling the inclusion criteria underwent pre-operative evaluation for surgery such as haemogram, urine examination, blood urea, blood sugar, ECG and serology for HIV and HbsAg. Pre-operative urinary infection was excluded by urinary microscopy and culture wherever indicated. Pap smear for all and endometrial sampling was done in indicated cases to exclude cervical and endometrial malignancy. Vaginal hysterectomy was done by standard technique under spinal anesthesia.

\section{Inclusion criteria}

Women undergoing vaginal hysterectomy with or without repair for benign gynecological conditions like utero vaginal prolapse, DUB, Adenomyosis, fibroid uterus $<16$ weeks size, cervical dysplasia etc.

\section{Exclusion criteria}

Women having UTI with pre-operative positive bacterial culture, urinary incontinence of any type-stress, urge or mixed, Comorbid illnesses like diabetes mellitus, chronic renal disease etc.

Any condition, which requires prolonged catheterization or prolonged IV fluid administration, like Kelly's stitch, iatrogenic bladder injury etc.

Cases were randomized using computer generated random number table into two groups:

- Group I: Foley's catheter and vaginal pack were removed 6 hours after surgery

- Group II: Foley's catheter and vaginal pack were removed 24 hours after surgery.

All patients received same type of prophylactic antibiotic Injection cefuroxime 1.5 grams I.V, 30-60 minutes before surgery.

All patients received spinal anesthesia and amount of blood loss and duration of surgery were noted for each patient. Hospital stay duration postoperatively for patients of both groups was recorded.

Pain was assessed using visual analog scale where score of 0-2 was mild, 3-6 was moderate, 7-8 was severe pain and 9-10 worst pain possible. Pain score was recorded 6 hours after surgery.

All patients were given Injection Ketorolac $30 \mathrm{mg}$ i.m (Thrice a day), Injection Tramadol $100 \mathrm{mg}$ i.v (twice a day) in the post-operative period for the first 24 hours.

Parameters studied in both groups were: incidence of symptomatic UTI, rates of re- catheterization and repacking. Subjective pain assessment was done using visual analog scale. Febrile morbidity was defined as two consecutive oral temperature readings of $>100.4$ degrees Fahrenheit measured 6 hours apart.

After urinary catheter removal and vaginal pack patients were encouraged to mobilize and void spontaneously. Time of first voiding was recorded, and pain scale was recorded 4 hours after surgery. Need for recatheterization was assessed by ability to pass urine at the 
end of 8 hours. If they were not able to void after 8 hours they were re-catheterized.

The diagnosis of symptomatic UTI will be based on the presence of significant bacteriuria accompanied by at least one of the following symptoms like fever, dysuria, increased frequency of micturition, urinary urgency and supra pubic pain.

On second postoperative day a midstream urine specimen was sent for microscopy and where pus cells were $\geq 5$, sample for urine culture and sensitivity was sent.

Patients with positive urine culture sensitivity were treated according to sensitivity and duration of hospital stay noted

\section{Statistical Analysis}

All data was entered into Microsoft excel 2011 and was analyzed using SPSS windows version 16. Need of repacking and re-catheterization at the end of 8-12 hours - Chi square test. Subjective pain assessment (Visual Analog Scale) at 8hours post operatively for all patients Chi square test. Febrile morbidity- 2 reading of $>100.4$ degree F 6 hours apart - Chi square test. Duration of hospital stay post-operatively - Mean, SD, student t-test.

\section{RESULTS}

Age, menopausal status and duration of surgery were almost same in both groups. The most common indication for $\mathrm{VH}$ was fibroid uterus $(32 \%)$ in group I and Adenomyosis (30\%) in group II.

Table 1: Indications for hysterectomy.

\begin{tabular}{|c|c|c|c|}
\hline $\begin{array}{l}\text { Indications for } \\
\text { hysterectomy }\end{array}$ & $\begin{array}{l}\text { Group I } \\
(\mathrm{n}=50)\end{array}$ & $\begin{array}{l}\text { Group II } \\
(n=50)\end{array}$ & \multirow{3}{*}{$\begin{array}{l}\mathrm{p} \\
\text { value }\end{array}$} \\
\hline $\begin{array}{l}\text { Abnormal uterine } \\
\text { bleeding }\end{array}$ & $7(14.0 \%)$ & $8(16.0 \%)$ & \\
\hline Fibroid & $16(32.0 \%)$ & $10(20.0 \%)$ & \\
\hline Adnenomyosis & $9(18.0 \%)$ & $15(30.0 \%)$ & \multirow{3}{*}{0.415} \\
\hline Dysplasia & $7(14.0 \%)$ & $4(8.0 \%)$ & \\
\hline Genital prolapse & $11(22.0 \%)$ & $13(26.0 \%)$ & \\
\hline
\end{tabular}

Vaginal Hysterectomy with pelvic floor repair (VH with PFR) was done in $26 \%$ and $45 \%$ of patients in group I and group II respectively.

Postoperative fever of >100.4-degree Fahrenheit was found to be $6 \%$ and $8 \%$ in group I and II respectively, which was not statistically significant.

UTI with pus cells >5 was found in $20 \%$ and $52 \%$ of group I and group II respectively and was statistically significant. Escherichia coli was commonest organisms in both groups.
Table 2: Urinary tract infection (number of pus cells).

\begin{tabular}{|llll|}
\hline Pus cells & Group I & Group II & p value \\
\hline $0-5$ & $40(80 \%)$ & $24(48 \%)$ & \\
\cline { 1 - 3 } 5 & $10(20 \%)$ & $26(52 \%)$ & \multirow{2}{*}{0.0008} \\
\hline Total & 50 & 50 & \\
\hline
\end{tabular}

Table 3: Urine culture and sensitivity.

\begin{tabular}{|c|c|c|c|}
\hline $\begin{array}{l}\text { Urine culture } \\
\text { and sensitivity }\end{array}$ & Group I & Group II & \multirow{2}{*}{ p value } \\
\hline $\begin{array}{l}\text { Culture not sent } \\
(0-5 \text { pus cells })\end{array}$ & $40(80 \%)$ & $24(48 \%)$ & \\
\hline Sterile & $5(10 \%)$ & $10(20 \%)$ & \multirow{2}{*}{0.003} \\
\hline Bacteria present & $5(10 \%)$ & $16(32 \%)$ & \\
\hline
\end{tabular}

Urine culture and sensitivity was positive in $10 \%$ and $32 \%$ of patients in group I and II respectively which was statistically significant.

Rate of recathetrization was high in group I (10\%) and none in group II.

Table 4: Recatheterization.

\begin{tabular}{|lll|}
\hline Recatheterization & Group I & Group II \\
\hline Not recatheterized & $45(90 \%)$ & $50(100 \%)$ \\
\hline Recatheterized & $5(10 \%)$ & 0 \\
\hline
\end{tabular}

Pain during the first voiding episode, first voiding time and urinary discomfort was almost similar in both groups.

Vaginal bleeding after pack removal was found in 3 patients who required repacking in group I and none in group II and there was no vault infection in either group. Ambulation time was similar in both groups. Hospital stay was less in group I compared to group I.

Table 5: Hospital stay duration post operatively (in days).

\begin{tabular}{|lllll|}
\hline Group I & N & Mean & SD & \\
\hline Group II & 50 & 3.48 & 0.544 & p value \\
\hline
\end{tabular}

\section{DISCUSSION}

Present study was done to compare Foley's catheter and vaginal pack removal in patients undergoing $\mathrm{VH}$ in 6 hours and 24 hours postoperatively. Traditional practice of keeping the urinary catheter and vaginal pack for prolonged duration post-operatively has changed with time as it became evident that prolonging the duration did not have any additional benefit, but it increased urinary tract infection and hospital stay. The best way to prevent urinary tract infection is to avoid putting the catheter if possible or to remove it as early as possible. 
The removal of catheter immediately after surgery had the disadvantage of difficulty in immediate ambulation and voiding due to the residual effect of regional anesthesia. To overcome the problem urinary catheter and vaginal pack were removed 6 hours after surgery and it was compared with removal 24 hours later of the same. Sample size in this study was 100 , randomized into two groups.

The mean age of the patient in the present study was 47.90 years in-group I and 50.18 years in group II. No variations were seen in indications for surgery, menopausal status or type of surgery. The commonest indication for vaginal hysterectomy in the present study was fibroid uterus $26 \%$ followed by utero vaginal prolapse in $24 \%$ of cases. $37 \%$ had vaginal hysterectomy with pelvic floor repair and $63 \%$ had vaginal hysterectomy alone.

Utero- vaginal prolapse was the commonest indication in studies by Sekhavat et al and Glavind et al. ${ }^{7,8}$ Summit et al above included only vaginal hysterectomy cases without pelvic floor repair whereas studies by Rajan et al and Glavind et al included cases with or without pelvic floor repair similar to the present study.,

Febrile morbidity was almost similar in both groups in present study, $6 \%$ and $8 \%$ in group I and II respectively. Summit et al in their study found much higher incidence of postoperative febrile morbidity of $24.5 \%$ in 24 hours group versus. $8 \%$ in no catheterization group. ${ }^{9}$ Rajan et al study morbidity was $7 \%$ and $4 \%$ in 3 hours versus 24 hours group respectively. ${ }^{10}$

In the present study urinary tract infection was $20 \%$ and $52 \%$ in group I and group II respectively and statistically significant indicating longer duration of catheterization resulted in higher incidence of urinary tract infection.

Table 6: Urinary tract infection.

\begin{tabular}{|c|c|}
\hline Studies & Percentage \\
\hline $\begin{array}{l}\text { Ahmed }^{11} \text { (Immediate versus } \\
\text { 6hours Versus } 24 \text { Hours) }\end{array}$ & $\begin{array}{l}1.4 \% \text { versus } 3.7 \% \\
\text { versus } 15 \%\end{array}$ \\
\hline $\begin{array}{l}\text { Nahed }{ }^{12}(12-24 \text { hours versus } 48- \\
72 \text { hours) }\end{array}$ & $6 \%$ versus $24 \%$ \\
\hline Rajan $^{10}$ (3hours versus 24 hours) & $26 \%$ versus $26 \%$ \\
\hline $\begin{array}{l}\text { Shrestha }{ }^{13} \text { (24hours versus } 72 \\
\text { hours) }\end{array}$ & $18 \%$ versus $30 \%$ \\
\hline $\begin{array}{l}\text { Shahnaz }{ }^{14} \text { ( } 24 \text { hours versus } 72 \\
\text { hours) }\end{array}$ & $\begin{array}{l}22.9 \% \text { versus } \\
34.3 \%\end{array}$ \\
\hline $\begin{array}{l}\text { SummittError! Bookmark not } \\
\text { defined. (no catheter versus } 24 \\
\text { hours) }\end{array}$ & $28 \%$ versus $16.3 \%$ \\
\hline $\begin{array}{l}\text { Present study ( } 6 \text { hours versus } 24 \\
\text { hours) }\end{array}$ & $20 \%$ versus $52 \%$ \\
\hline
\end{tabular}

Most of the studies reported higher incidence of urinary tract infection, when urinary catheter was kept for a longer time similar to present study except in Summit et al study observed incidence of urinary tract infection in women in whom post-operative indwelling catheter was not kept. ${ }^{9}$

In the present study Escherichia coli was isolated in the majority of positive cultures being $60 \%$ versus $62.5 \%$ in the group I and group II respectively. Thakur et al, Shrestha et al, Joshi et al in their study also found Escherichia coli to be the most frequent organism in the positive urine cultures. ${ }^{13,15,16}$

Summit et al observed that none of the patients required re-catheterization in no catheter group compared to catheterization group, among whom two patients required re-catheterization following vaginal hysterectomy. ${ }^{9}$ The study concluded that indwelling catheterization is not required after routine uncomplicated vaginal hysterectomy. After vaginal surgery patient may be unable to pass urine on her own and may have retention of urine due to post-operative tissue swelling, pain, transient bladder atony, hematoma and also due to the hemostatic vaginal pack.

In the present study re-catheterization rate was $10 \%$ in group I and none in group II. In the present study, visual analog scale was used to assess pain experienced during first voiding episode. Both 6 hours and 24 hours group experienced moderate amount of pain, which was statistically insignificant.

Duration from removal of catheter post operatively to patient voiding spontaneously was taken as First void time. In the present study majority of patients voided within first 5 hours of catheter removal in both groups. Mean duration in hours was 4.07 hours \pm 0.931 in group I and 4.3 hours \pm 1.129 in group II.

Table 7: Rate of recatheterization.

\begin{tabular}{ll|}
\hline $\begin{array}{l}\text { Studies } \\
\text { Rajan }^{10} \text { (3hours versus 24hours) }\end{array}$ & Percentage \\
\hline $\begin{array}{l}\text { Shrestha } \\
\text { hours) }\end{array}$ & (24hours versus 72 \\
$\begin{array}{l}\text { Summit } \\
\text { hours) }\end{array}$ & $6 \%$ versus 0 \\
\hline $\begin{array}{l}\text { Shahnaz } \\
\text { hours) }\end{array}$ & 0 versus 2 \\
\hline $\begin{array}{l}\text { Present study (6 hersus } 24 \\
24 \text { hours) }\end{array}$ & $31.4 \%$ versus \\
\hline
\end{tabular}

Patients undergoing vaginal hysterectomy with pelvic floor repair were more likely to develop post-operative voiding dysfunction, which may be due to anterior colporrhaphy and bladder mobilization.In the present study majority experienced moderate discomfort whilst other studies found that majority experienced only mild amount of discomfort.

In the present study there was no incidence of vault infection in either of the groups. Vaginal repacking was 
required in $6 \%$ of patients in group I and none in group II. The patients who required repacking had undergone vaginal hysterectomy with pelvic floor repair.

Subramanya et al study found no particular benefits of placing vaginal pack post operatively in patients undergoing vaginal hysterectomy. ${ }^{17}$

Rajan et al reported no patient experienced vaginal bleeding following pack removal, however, in the 24 hour removal group $1 \%$ had to be repacked. This observation was in contrast to present study. ${ }^{9}$ Thiagamoorthy et al recommended in their study to pack the vagina post operatively suggesting it might reduce hematoma formation post operatively. ${ }^{18}$

There was no significant difference in the operation time and ambulation time in both the groups of present study. Mean ambulation time after catheter removal in present study was 10.32 hours in group I and 10.10 hours in group II. Ouladsahebmadarek et al (immediate versus 24 hours) found mean of 15.53 hours versus. 24.36 hours respectively. ${ }^{19}$

Duration of hospital stay post operatively in present study was 3.48 versus 3.98 days in group I and group II respectively. Choudhary et al found hospital stay of 4.68 days in short duration compared to 6.98 days in longer duration catheterization. ${ }^{20}$ Nahed (12-24hrs group) reported that majority ambulated within 4-8 hours versus. 48-72 hours where majority ambulated in 14-18 hours. ${ }^{12}$

Sample size was small in the present study and it also excluded comorbidities like diabetes mellitus, hypertension etc. The study included women who underwent vaginal hysterectomy with and without pelvic floor repair.

\section{CONCLUSION}

The question of how long urinary catheter and vaginal pack should remain in-situ after vaginal hysterectomy with or without pelvic floor repair has been debated for several years and has not yet been resolved. Risks and benefits have to be weighed. Early removal of urinary catheter was associated with less risk of urinary tract infection but with slightly increased risk of recatheterization.

Early removal of vaginal pack was associated with increased risk of vaginal bleeding requiring repacking in case of vaginal hysterectomy with pelvic floor repair. Best way to prevent catheter related morbidity is to remove it as early as possible.

Vaginal pack may be necessary in cases of vaginal hysterectomy with pelvic floor repair when vaginal oozing is anticipated. Further large comparative studies are necessary to support the practice of short-term catheterization of 3-6 hours.

\section{Recommendations}

Early removal of Foley's and vaginal pack is recommended in uncomplicated Vaginal Hysterectomy to reduce post-operative morbidity.

\section{Funding: No funding sources}

Conflict of interest: None declared

Ethical approval: The study was approved by the Institutional Ethics Committee

\section{REFERENCES}

1. Wu JM, Wechter ME, Geller EJ, Nguyen TV, Visco AG. Hysterectomy rates in the United States, 2003. Obstet and Gynecol. 2007 Nov 1;110(5):1091-5.

2. American College of Obstetricians and Gynecologists. Choosing the route of hysterectomy for benign disease. ACOG Committee Opinion. 2009 Nov(444):1156-8.

3. Linkov F, Sanei-Moghaddam A, Edwards RP, Lounder PJ, Ismail N, Goughnour SL et al. Implementation of Hysterectomy Pathway: Impact on Complications. Womens Health Issues. 2017 Jul Aug;27(4):493-8.

4. Dorsey JH, Steinberg EP, Holtz PM. Clinical indications for hysterectomy route: patient characteristics or physician preference? Am J Obstet Gynecol. 1995;173(5):1452-60.

5. Schiotz HA. [Catheterization routines after gynecologic surgery in Norway]. Tidsskr Nor Laegeforen. 1991;111(7):841-3.

6. Warren JW. Catheter-associated urinary tract infections. Infectious disease clinics of North America. 1997;11(3):609-22.

7. Sekhavat L, Farajkhoda T, Davar R. The effect of early removal of indwelling urinary catheter on postoperative urinary complications in anterior colporrhaphy surgery. Aust N Z J Obstet Gynaecol. 2008;48(3):348-52.

8. Glavind K, Mørup L, Madsen H, Glavind J. A prospective, randomised, controlled trial comparing 3 hour and 24-hour postoperative removal of bladder catheter and vaginal pack following vaginal prolapse surgery. Acta Obstet Gynecol Scand. 2007;86(9):1122-5.

9. Summitt RL Jr, Stovall TG, Bran DF. Prospective comparison of indwelling bladder catheter drainage versus no catheter after vaginal hysterectomy. Am J Obstet Gynecol. 1994;170(6):1815-8.

10. Rajan P, Raghavan SS, Sharma D. Study comparing 3 hour and 24-hour post-operative removal of bladder catheter and vaginal pack following vaginal surgery: a randomised controlled trial. BMC Women's Health. 2017;17:78-83.

11. Ahmed MR, Sayed Ahmed WA, Atwa KA, Metwally L. Timing of urinary catheter removal after uncomplicated total abdominal hysterectomy: a prospective randomized trial. Eur J Obstet Gynecol Reprod Biol. 2014;176:60-3. 
12. Nahed F. K. Effect of Early versus Late removal of Urinary Catheter on Urinary Outcome after Hysterectomy. J Am Sc. 2011;7(1): 277-81.

13. Alessandri F, Mistrangelo E, Lijoi D, Ferrero S, Ragni N. A prospective, randomized trial comparing immediate versus delayed catheter removal following hysterectomy. Acta Obstetricia et Gynecolog Scandinavica. 2006 Jun;85(6):716-20.

14. Shrestha B, Marhatha R, Kayastha S, Jaishi S. Shortterm versus long-term catheterization after vaginal prolapse surgery. Nepal Medical College J: NMCJ. 2013;15(2):102-05.

15. Shahnaz A, Elham R, Kambiz A, Sara K. Comparison of 1 Versus 3 Days Post-Operative Catheterization After Anterior Colporrhaphy. Asian J Pharma Res Health Care; 2016:8(S1),1-6.

16. Thakur N, Gurung G, Rana A. A randomized controlled trial comparing short-term versus longterm catheterization after vaginal prolapse surgery. Nepal J Obstet Gynaecol. 2007;2(1):29-34.

17. Joshi B, Aggarwal N, Chopra S, Taneja N. A prospective randomized controlled comparison of immediate versus late removal of urinary catheter after abdominal hysterectomy. J Midlife Health. 2014;5(2):68-71.

18. Subramanya J, Curtiss N, Balachandran A, Duckett J. Should we use a vaginal pack to reduce blood loss at the time of prolapse surgery? Europ J Obstet Gynecol Reprod Biol. 2006;206:181-3.

19. Thiagamoorthy G, Khalil A, Cardozo L, Srikrishna S, Leslie G, Robinson D. The value of vaginal packing in pelvic floor surgery: a randomised double-blind study. Int Urogynecol J. 2014;25(5):585-91.

20. Ouladsahebmadarek E, Sayyah-Melli M, JafariShobeiri M. A randomized clinical trial to compare immediate versus delayed removal of foley catheter following abdominal hysterectomy and laparotomy. Pak J Med Sci. 2012;28(3):380-3.

21. Choudhury FR, Rashid M, Rumana R, Uddin AZ, Ava NN. Short Term Versus Long Term Catheterization after Urogenital Prolapse Surgery. J Shaheed Suhrawardy Med College. 2012 Oct;3(2):41-3.

Cite this article as: Gupta A, Rani RP. A prospective randomized trial to compare side effects of early versus late removal of Foley's catheter and vaginal pack following vaginal hysterectomy. Int $\mathbf{J}$ Reprod Contracept Obstet Gynecol 2018;7:2693-8. 